\title{
Change of editorial assistant
}

\author{
Christian Pierdzioch • Christian Richter • \\ Paul J. J. Welfens • Holger C. Wolf
}

Published online: 24 August 2013

(C) Springer-Verlag Berlin Heidelberg 2013

For 6 years Thomas Domeratzki - conducting research and teaching at the Schumpeter School of Business and Economics/University of Wuppertal - has been our outstanding editorial assistant. During these years the impact factor of journal has steadily risen alongside its global dissemination; the top journal articles have more than a thousand downloads. We are very grateful to Mr. Domeratzki for his commitment to the journal, helping in attracting and publishing high quality research. We wish him all the best for his future career.

We are happy to welcome Mr. Vladimir Udalov as the new editorial assistant. On the occasion of the transition, we would also like to express our sincere gratitude to our outstanding academic referees, who have provided invaluable support for our mission to publish high quality papers with economic policy relevance.

We will continue to emphasize a global outreach, a focus on crucial theoretical and empirical issues and in particular debates on alternative policy approaches. International Economics as a field has witnessed some analytical progress, however, we cannot be satisfied with the state of economics as a science-too many serious problems and challenges have been overlooked in the first decade of the 21 st century.

Hamburg, London, Wuppertal and Washington DC, July 2013

Christian Pierdzioch, Christian Richter, Paul JJ Welfens and Holger Wolf

\footnotetext{
C. Pierdzioch

Helmut-Schmidt-University, Hamburg, Germany

C. Richter

Kingston University, Kingston upon Thames, UK

P. J. J. Welfens $(\bowtie)$

European Institute for International Economic Relations, University of Wuppertal,

Wuppertal, Germany

e-mail: Welfens@uni-wuppertal.de

H. C. Wolf

Georgetown University, Washington, DC, USA
} 